\title{
Spectrum of Congenital Renal Anomalies
}

\author{
Authors \\ Dr Subhashree Dash ${ }^{1}$, Dr Subhasish Panda ${ }^{2}$, Dr Savitri Bhagat ${ }^{3}$, Dr B.B.Panda ${ }^{4}$ \\ ${ }^{1,2}$ PG Student, Dept of Radiodiagnosis, VIMSAR, Burla, India \\ ${ }^{3}$ Prof \& HOD, Dept of Radiodiagnosis, VIMSAR, Burla, India \\ ${ }^{4}$ Assoc. Prof, Dept of Radiodiagnosis, VIMSAR, Burla, India \\ Corresponding Author \\ Dr Subhasish Panda
}

Email: drsubhasishpanda15@gmail.com Ph: 7008291101

\begin{abstract}
Introduction: Congenital anomalies of the kidney are a common renal pathology diagnosed in childhood or middle age. The varieties of these anomalies and their ensuing complications often pose a challenge to accurate diagnosis and timely management.

Methods: The spectrum of congenital anomalies and their complications were evaluated in this observational cross-sectional study. Ultrasonography and Color Doppler was used along with CT Scan and IVP wherever necessary. The complications produced by these anomalies were also evaluated.

Results: A total of thirty cases were observed over a period of one year. Ectopic kidney was the most commonly observed anomaly followed by duplex collecting system, horse-shoe kidney and autosomally dominant polycystic kidney disease. Calculus, hydronephrosis, calculostasis and pyelonephritis were the most common complications observed.

Conclusion: Radiographic imaging using Ultrasound with Doppler is a very good modality to identify the spectrum of congenital renal anomalies and its complications.

Keywords: kidney, horseshoe, ectopic, duplex, polycystic.
\end{abstract}

\section{Introduction}

Congenital anomalies of the urinary tract occur in 3 to 6 per 1000 live births. They are major cause of end-stage renal disease in children and are responsible for stone formation, infection, hypertension and renal failure in adulthood causing great morbidity and mortality.

The kidneys play a pivotal role in maintaining body homeostasis and congenital anomalies of the kidney can pose a significant impact on the quality of life and economic burden of the patients. The kidneys develop from two sources, metanephric blatema and ureteric bud. Metanephric blastema forms renal cortex and medulla while the ureteric bud forms calyces and collecting system. Congenital malformations of the kidneys can thus be classified into four broad categories: 1 . abnormalities in number like supernumerary kidney, unilateral renal agenesis, 2. abnormalities in parenchymal development like adult polycystic kidney disease, autosomal recessive polycystic kidney disease, 3. aberrant embryonic migration 
like horseshoe kidney, ectopic kidney and 4. abnormalities of the collecting system like duplex collecting system $^{(1)}$.

These are detected incidentally with patients presenting with symptoms not always related to the renal cause. Early detection of such anomalies can help prevent patients from landing up in a variety of complications and ultimately end stage renal disease. Ultrasound plays a very important role in detection of such congenital anomalies which requires further confirmation by intravenous pyelogram or Computerised tomography.

\section{Materials \& Methods}

This was a Cross-sectional Observational Study conducted at V.S.S. Institute of Medical Sciences and Research, Burla, Sambalpur over the period from July 2016 to February 2017. All patients referred to the Out Patients Department of Radiodiagnosis for ultrasonographic evaluation of various complaints of abdominal origin were screened for the confirmation of any abdominal pathology. Patients who revealed presence of Congenital Abnomalies of the Kidney were included in the study. Anomalies of ureter and the bladder were not included from the study.

The demographic profile, medical history and chief complaints of each patient was recorded in the Case Record Form after taking their Informed Consent. The Ultrasonograhic Findings (grey scale), Colour Doppler Findings were recorded. Ultrasound and Colour Doppler evaluation was carried out using Phillips HD machine. Those patients requiring further investigations were tested with Computerised Tomography and IV Pyelography.

\section{Results}

A total of 30 cases of congenital renal anomalies were detected using gray scale ultrasonography and colour doppler study.

The demographic profile of study subjects is depicted in table 1. Most of the patients belonged to the middle age group (40-60 yrs), with no gender predilection.
Table 1 Demographic Profile of Patients with Congenital Renal Anomalies

\begin{tabular}{|l|c|c|c|c|}
\hline Age Group & Males & Females & Total & Percentage \\
\hline $0-10$ yrs & - & 2 & 2 & 6.6 \\
\hline $11-20$ yrs & 3 & 1 & 4 & 13.2 \\
\hline $21-30$ yrs & 1 & 3 & 4 & 13.2 \\
\hline $31-40$ yrs & 2 & 1 & 3 & 9.9 \\
\hline $41-50$ yrs & 4 & 3 & 7 & 23.3 \\
\hline $51-60$ yrs & 5 & 3 & 8 & 26.6 \\
\hline $61-70$ yrs & 2 & - & 2 & 6.6 \\
\hline $71-80$ yrs & - & - & 0 & 0 \\
\hline TOTAL & 17 & 13 & 30 & 100 \\
\hline
\end{tabular}

The Chief Complaints of the study subjects is depicted in table 2 . The most common complaint was observed to be vague abdominal pain.

Table 2 Chief Complaints of the Study Subjects

\begin{tabular}{|l|c|c|}
\hline Chief Complaints & $\begin{array}{c}\text { Number } \\
\text { of Cases }\end{array}$ & Percentage \\
\hline Abdominal pain & 12 & $40 \%$ \\
\hline Fever & 6 & $20 \%$ \\
\hline Haematuria & 3 & $10 \%$ \\
\hline Back pain & 3 & $10 \%$ \\
\hline Palpable mass & 2 & $6.6 \%$ \\
\hline Other minor complaints & 3 & $10 \%$ \\
\hline Asymptomatic & 1 & $3.3 \%$ \\
\hline Total & 30 & $100 \%$ \\
\hline
\end{tabular}

The spectrum and frequency of congenital renal anomalies observed over the period of one year is depicted in table 3. Most commonly anomaly observed was ectopic kidney and least common was unilateral supernumerary kidney and renal agenesis.

Table 3 Spectrum of Congenital Renal Anomalies

\begin{tabular}{|l|c|c|}
\hline $\begin{array}{l}\text { Type of Congenital } \\
\text { Anomaly }\end{array}$ & $\begin{array}{c}\text { Number of } \\
\text { Cases }\end{array}$ & Percentage \\
\hline Ectopic Kidney & 12 & 40 \\
Uncrossed & 7 & 23.3 \\
Crossed unfused & 2 & 6.6 \\
Crossed fused & 3 & 10 \\
\hline Duplex Collecting System & 6 & 20 \\
\hline Horseshoe kidney & 4 & 13.4 \\
\hline Autosomally Dominant & 4 & 13.4 \\
Polycystic Kidney Disease & & \\
\hline Supernumerary Kidney & 2 & 6.6 \\
\hline Renal Agenesis & 2 & 6.6 \\
\hline
\end{tabular}

Renal Complications were associated in 6 out of the 30 cases, most common being a calculus. They are depicted in table 4. 
Table 4 Associated Complications of Congenital Renal Anomalies

\begin{tabular}{|l|c|c|}
\hline Complications & Number of Cases & Percentage \\
\hline Calculus & 3 & 10 \\
\hline $\begin{array}{l}\text { Calyectasis / } \\
\text { Hydronephrosis }\end{array}$ & 2 & 6.7 \\
\hline Pyelonephritis & 1 & 3.3 \\
\hline
\end{tabular}

\section{Discussion}

A variety of developmental anomalies are known to involve urinary system, kidneys being the most common. Although these anomalies can present clinically secondary to urinary tract obstruction, infection or trauma, they are usually incidentally detected $^{(2)}$.

The most common presenting symptom was that of vague abdominal pain in our study. Literature survey reveals that abdominal pain is often the presenting symptom along with urinary complaints $^{(3)}$.

The most common congenital renal anomaly observed in our study was ectopic kidney (a disorder of migration) seen in $40 \%$ of cases, which was in contrast to a study by Tulika Gupta et al who found horseshoe kidney as the most common anomaly ${ }^{(4)}$. In our study, disorders of migration were 11 in number of which 7 were ectopic kidney and 4 were horseshoe kidney.

Literature review reveals that ectopic kidney is observed in 1 in 724 paediatric autopsies where the kidneys fail to ascend (pelvic kidneys). These kidneys are usually small and abnormally rotated. In our study, 7 were uncrossed while 5 were crossed (3 fused and 2 unfused). They derive their blood supply from regional arteries such as internal iliac or common iliac artery. In this study, the most common blood supply was from the internal iliac arteries (Fig 1). Due to short ureter and poor drainage ectopic kidneys are prone to infection and stone formation, none of which were present in our study ${ }^{(5)}$.
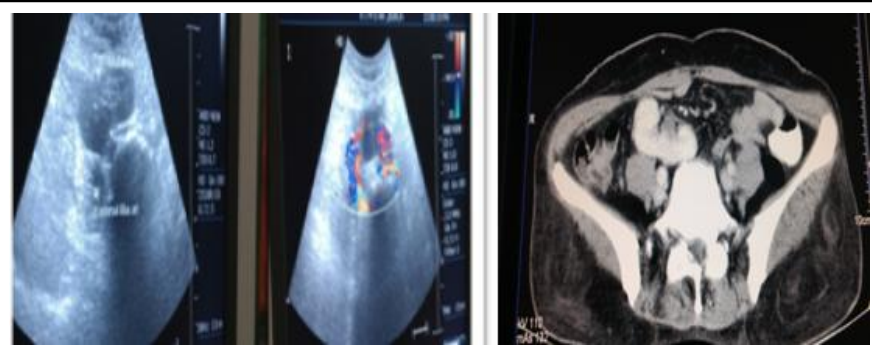

Fig 1. Ultrasound images show right kidney in ectopic location anterior to vertebral body and right internal iliac artery with origin of right renal artery from right internal iliac artery. Corresponding CT image is shown on the right.

Horseshoe kidney was observed in $13.4 \%$ of cases in our study. Its incidence in general population is $0.01 \%$ to $0.25 \%$ and is more common in $\operatorname{men}^{(6)}$. It occurs because the intermediate mesoderm that gives rise to metanephric blastema fails to separate $^{(7)}$. As a result, the lower poles of both kidneys are fused in midline anterior to great vessels. Normal ascent of kidney is arrested by the inferior mesenteric artery and hence, the kidneys are low lying. Horseshoe kidneys are predisposed to ureteropelvic junction obstruction, infection and stone formation ${ }^{(8)}$. These complications were not observed in any of our study subjects (Fig 2).
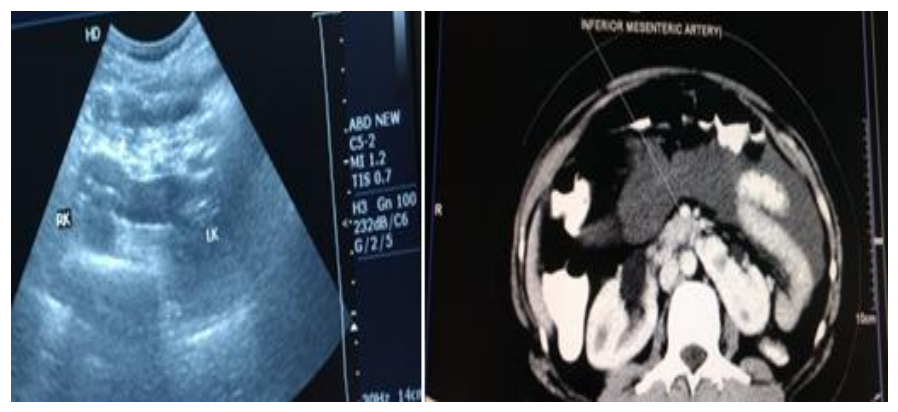

Fig 2. Abdominal USG showing fusion of Lower poles of right and left kidneys at midline.

Corresponding Computerised Tomography image is shown on the right consistent with horseshoe kidney.

In our study, the next in prevalence was collecting system anomalies of which 6 cases of duplex collecting system were observed. It is reported incidence is $0.5-1 \%$ of all live births. Duplication is complete when there are two separate collecting system with their own draining ureter and separate ureteral orifice. Here, the ureter draining lower pole has more perpendicular course making it 
prone to reflux ${ }^{(9)}$. Duplication is incomplete when ureters join and enter the bladder through single ureteral orifice. In our study, all cases had incomplete duplication (Fig 3).

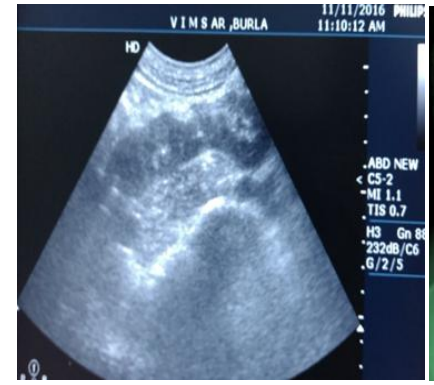

Fig 3(a)

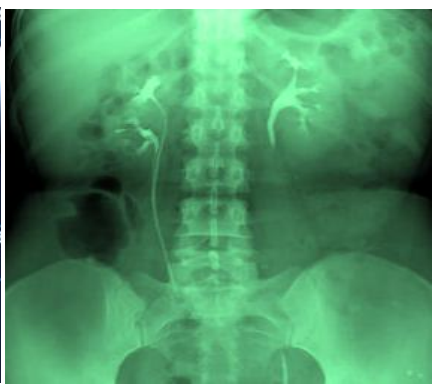

Fig 3(b)
Fig 3(a) showing two echogenic renal sinuses with a intervening bridging parenchyma.

Fig 3 (b) IVP image confirms presence of duplex collecting system on the right.

Renal parenchymal anomaly of the autosomal dominant adult polycystic kidney disease was observed in $4(13.4 \%)$ of cases. It is the most common hereditary renal disorder and with an incidence of 1:500 to 1:1000. Kidneys are enlarged and are replaced by well defined asymmetrical cysts of varying sizes with imperceptible walls, posterior acoustic enhancement and lateral shadowing and not communicating with each other on ultrasound ${ }^{(10)}$. When complicated by haemorrhage internal echoes may appear in the cysts. Other complications are infection, stone formation, cyst rupture and obstruction. These were not observed in any of our cases (Fig 4). Associated anomalies include liver cysts (30-60\%), pancreatic cysts $(10 \%)$, splenic cysts (5\%), cerebral berry aneurysms (18-40\%), abdominal aortic aneurysms and colonic diverticula ${ }^{(10)}$. Of these, liver cysts were found in two of our cases with seminal vesical cysts in one patient. The most common associated finding was that of a calculus seen in 3 cases of autosomal dominant polycystic kidney.

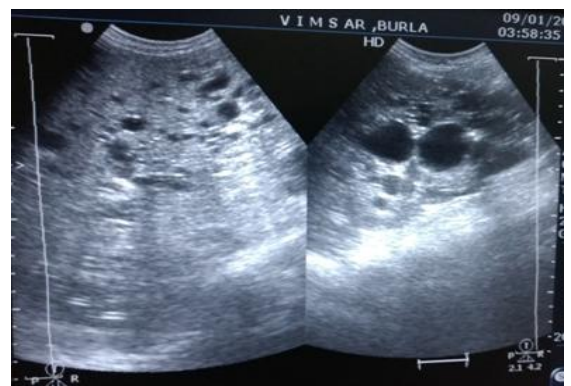

Fig 4. Ultrasound image on the left shows multiple cysts in liver parenchyma. Figure to the right shows multiple cysts of different sizes in right kidney. Diagnosis: Autosomal Dominant Polycystic Kidney Disease.

Autosomal recessive polycystic kidney disease, another type of renal parenchymal anomalies was observed in $13.4 \%$ of cases. Characteristic imaging features on antenatal ultrasound include enlarged reniform bilateral kidneys demonstrating increased echogenicity especially of the medullary pyramids. Cysts are usually too small to be discernible as was the case in our patient. Some reports suggest visualisation of multiple cysts/tubular structures representing ectatic collecting ducts, a finding seen in our study ${ }^{(11)}$.

Supernumerary kidney and Unilateral renal agenesis (abnormalities in number) were seen in 2 cases $(6.6 \%)$ each. Supernumerary kidney is exceedingly rare anomaly with less than 100 cases reported in various literatures. This anomaly arises when two ureteric buds reach metanephric blastema which then divides to form two kidneys (12). Non urological anomalies like coarctation of aorta, ventricular septal defects, imperforate anus, meningomyelocoele may be associated with it $^{(7)}$. None of these were encountered in our study (Fig 5). Supernumerary kidneys are usually smaller than normal and found below, in front or behind the normal kidneys.

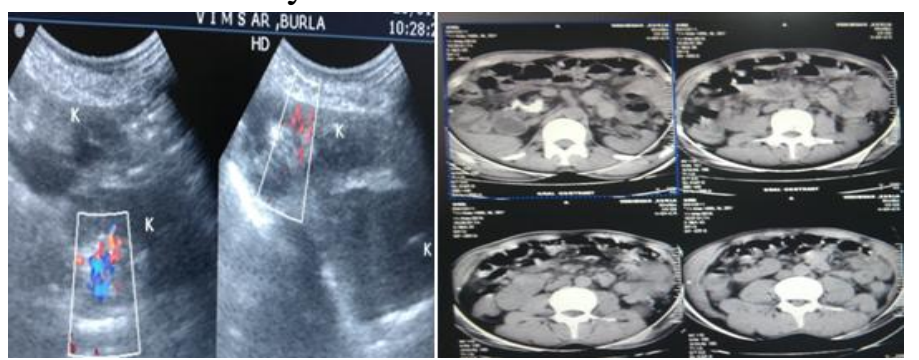

Fig 5. Ultrasound image on the left showing two reniform structures noted in right renal fossa with 
fat planes separating them with hilar vascularity. Corresponding CT scan image confirming the diagnosis of supernumerary kidney.

Unilateral renal agenesis was found in $2(6.6 \%)$ cases, is usually detected incidentally, as was in our study. Its incidence is reported to be 1 in 3000 live births ${ }^{(13)}$. Embryologically renal agenesis is due to failure of proper development of metanephros resulting in its complete absence which may be due to an early vascular insult ${ }^{(14)}$. Usually there is compensatory hypertrophy of solitary kidney which was observed in our study (Fig 6). Renal agenesis is usually associated with trisomy 21 and 22, Mullerian anomalies, congenital heart disease, club foot, and VACTREL ${ }^{(15)}$. In our study, only Mullerian anomaly (Herlyn Werner Wunderlich syndrome) was associated with renal agenesis.

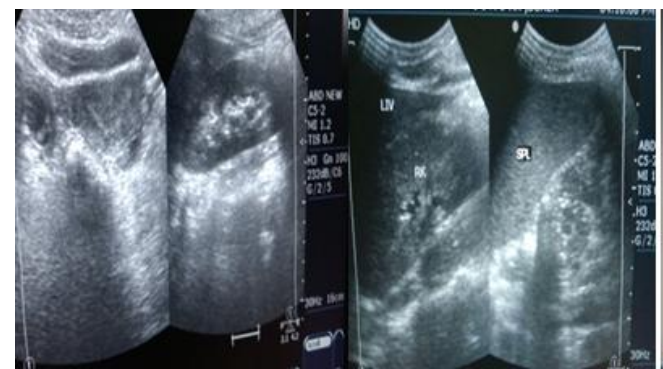

Fig 1(a)
Fig 1(b)

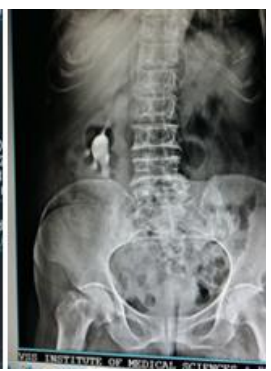

Fig 1 (c)
Fig 6(a) Image on left shows uterus with two separate endometrial echoes. Haematocolpos was also present. Fig 6(b) shows absence of left kidney in left renal fossa. Fig 6(c) IVP showing nephrogram of the right kidney 5 minutes after IV contrast administration. No nephrogram of left kidney could be visualised. Diagnosis was Herlyn Werner Wunderlich Syndrome.

\section{Conclusion}

USG examination of the abdomen is often the first imaging modality in detection of the variety of congenital anomalies as observed in our study. CT Scan and IVP are helpful in confirmation of these anomalies detected by USG. In our study, the most common renal anomaly was that of ectopic kidney followed by duplex collecting system. Every radiologist must be familiar with the imaging features and potential complications for successful diagnosis to foster timely management.

\section{References}

1. Daneman A, Alton DJ. Radiographic manifestations of renal anomalies. Radiol Clin North Am. 1991;29:351-363.

2. Kemper MJ, Müller-Wiefel DE. Renal function in congenital anomalies of the kidney and urinary tract. Curr Opin Urol 2001;11:571-5.

3. M Muttarak and $\mathrm{T}$ Sriburi. Congenital renal anomalies detected in adulthood. Biomed Imaging Interv J. 2012 Jan-Mar; 8(1): e7.

4. Tulika Gupta, Suresh K Goyal, Anjali Aggarwal, Kunal Chawla et al. Congenital Renal Anomalies in Indian Population. Journal of Postgraduate Medicine, Education and Research. January-March 2017;51(1):12-16.

5. Rascher W, Rosch WH. Congenital abnormalities of the urinary tract. Oxford Textbook of Clinical Nephrology. Oxford: Oxford University Press, Inc, 2005:140212.

6. Gupta M, Pandey AK, Goyal N (2007). "Horseshoe kidney--a case report". Nepal Medical College Journal. 9 (1): 63-6.

7. Janda GM, Nepple KG, Cooper CS, Austin JC. Supernumerary kidney in a child with OEIS complex. Urology. 2009;74(2):305307.

8. Naveena $\mathrm{S}$ et al. Horseshoe kidney: a case. Int J Res Med Sci. 2013Aug;1(3):304-307.

9. Nagpal $H$ et al. Unilateral duplex collecting system with incomplete duplication of ureter - a case report. International Journal of Research in Medical Sciences. May;5(5):2254-2256

10. Nahm AM, Henriquez DE, Ritz E. Renal cystic disease (ADPKD and ARPKD). Nephrol. Dial. Transplant. 2002;17 (2): 311-4. 
11. Mercado-deane MG, Beeson JE, John SD. US of renal insufficiency in neonates. Radiographics. 22 (6): 1429-38.

12. Tada Y., Kokado Y., Hashinaka Y. Free supernumerary kidney: a case report and review. J Urol. 1981;126:231-232.

13. Laurichesse Delmas H, Kohler M, Doray $\mathrm{B}$, et al. Congenital unilateral renal agenesis: Prevalence, prenatal diagnosis, associated anomalies. Data from two birthdefect registries. Birth Defects Res 2017; 109:1204.

14. Mercado-deane MG, Beeson JE, John SD. US of renal insufficiency in neonates. Radiographics. 22 (6): 1429-38.

15. Del Vescovo R, Battisti S, Di Paola V etal. Herlyn-Werner-Wunderlich syndrome: MRI findings, radiological guide (two cases and literature review), and differential diagnosis. BMC Med Imaging. 2012;12 (1):4. 